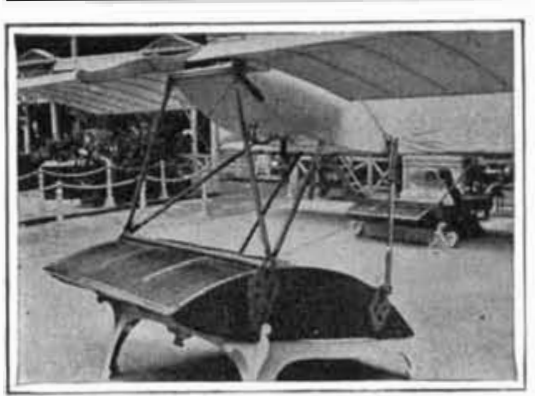

Float of Voisin hydro-aeroplane.

T IIE third International Aviation Salon was held in Paris from December 16th to January 2nd. It was noteworthy that, as compared with the exhibitions of previous years, the collection of exhibits on view was more or less international in character. The exhibition was held in the Grand Palais, and was opened by President Fallières, who was conducted through the Salon by a committee headed by MI. Robert Esnault-Pelterie. As heretofore, the exhibition was organized by the Chambre Syndicale des Industries Aeronautiques, under the auspices of the International Aeronautic Federation and the Aero Club of France.

Although the advance in the performance of aeroplanes has been very decided during 1911, the improvement in the machines themselves has kept pace with it. Besides great structural changes, improvements have been made looking to the comfort of pilots and passengers; and given the Deutsch "taxicab" to begin with, the coach builders will soon be called upon to make closed bodies for aeroplanes the same as they do for automobiles.

The influence of the monoplane upon the biplane appears in the adoption by many prominent biplane builders of the long covered fuselage, or body, of the monoplane, with the propeller in front, in place of the four spars that were formerly used to support the tail. The Farman brothers still use the latter arrangement, but the lower plane of the Maurice Farman biplane has been very much shortened (see photo.) until it is now no. longer than the lower plane of the Breguet, which, by the way, was the first biplane to adopt the monoplane body and propeller placing, several years ago. In order to be in line with the new idea of inclosing the motor, Louis Breguet, two of whose biplanes carried off the honors in the recent military competition, exhibited the machine with covered fourcylinder, water-cooled motor shown in one illustration. The radiator can be seen beside the body. When the bonnet was raised slightly, it gave the front end of the machine the resemblance of a whale with open jaws, and created much amusement. Another Breguet novelty was a side door in the body and a ladder leading up thereto, as shown in one of the small illustrations.

The inclosing of the motor, when a revolving cylinder Gnome was used, was more or less complete in most cases. The complete inclosure of the engine in a very neat manner is shown on the Morane monoplane. The entire body of this machine, designed by Ingineer Saulnier, is of pressed steela marked advance indeed in fuselage construction, comparable only with the pressed steel autoinobile frame. Led by pressed Esnauit-Pelterie, whose R.E.P. monoplanes have triangular bodies of steel tubing (see Supplement No. 1871), a goodly number of the French manufacturers are adopting metal construction. A monoplane with sheet metal wings was on exhibition. Thus the ScIENTIFIC AMERIcav all-steel monoplane racer, illustrated in these columns a year and a half ago, is gradually leing approached by the builders. The narrow wings we showed on this machine were approximated by the Blériot racers in the International Cup race last July, and also by the Kaufmann monoplane in the recent Salon. The latter and the Paulhan-Tatin monoplane were the only machines exhibited with disk wheels, i. e., wheels with cloth-covered spokes to reduce air resistance. Emile Train, whose monoplane killed Minister of War Ber-

\title{
The Third Aviation Salon at Paris
}

Interesting Aeroplanes and Their Constructional Details

By Stanley Yale Beach

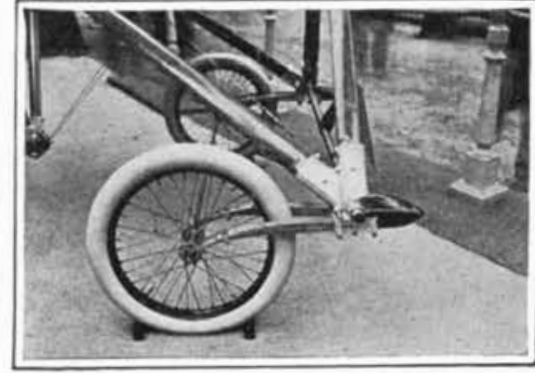

Leaf-spring fork of Blériot monoplane.

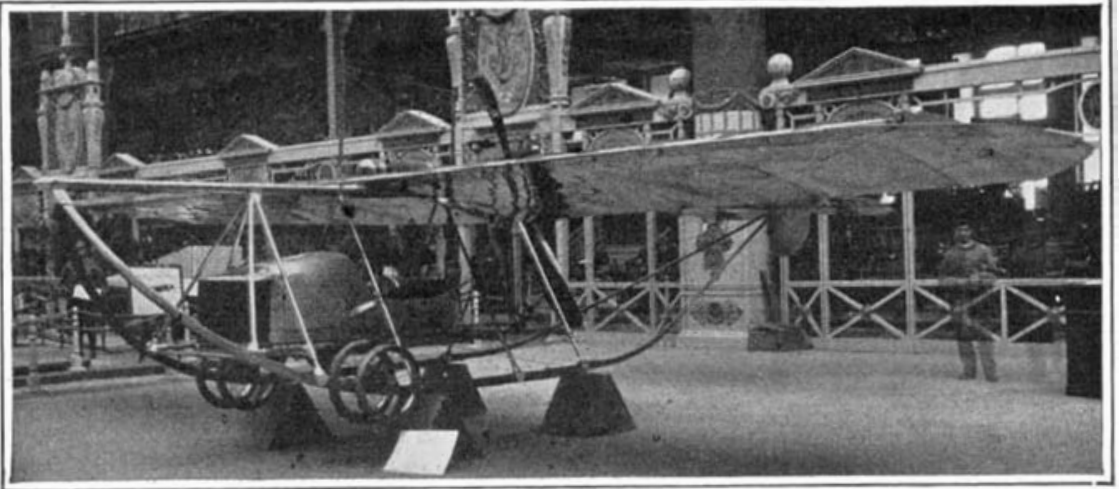

The "Tubavion" monoplane with underslung car and motor. A single steel tube forms the backbone, the propeller being mounted on it behind the main plane

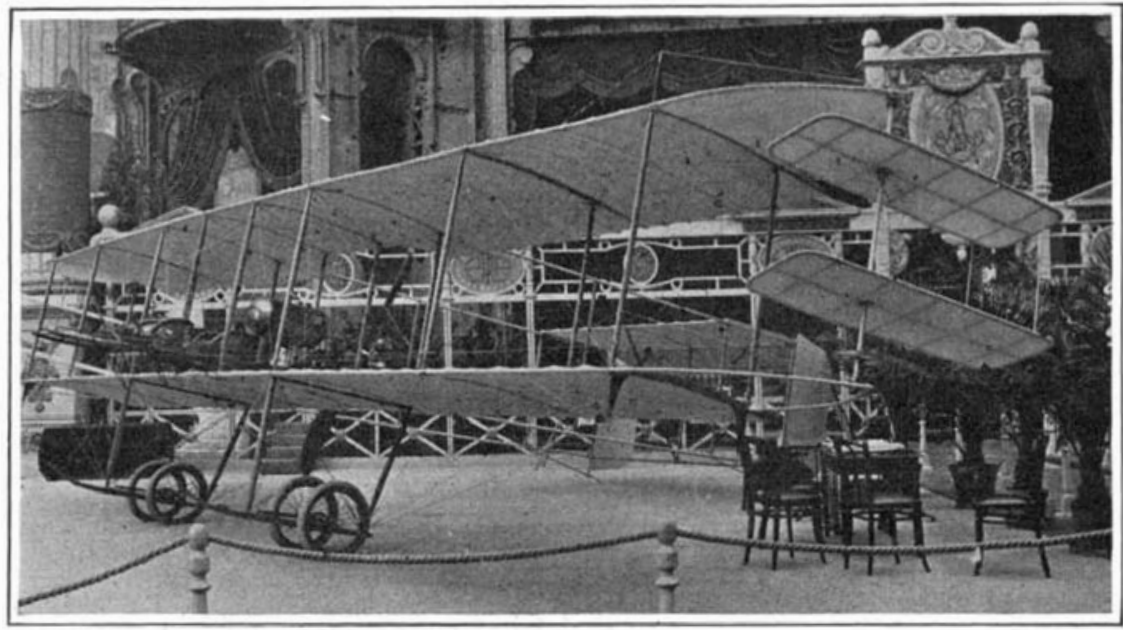

Farman biplane fitted with new form of stabilizing planes.

The two planes are mounted on $a$ vertical shaft which is turned to swing them outward.

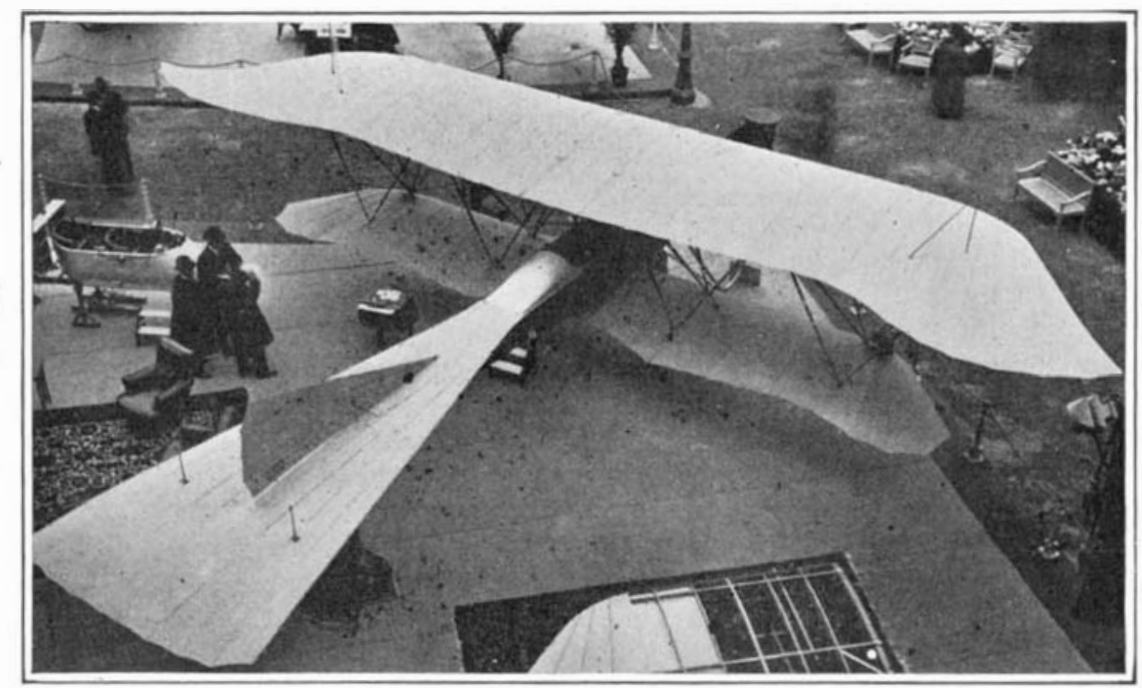

“Albatzoss" biplane (German) viewed from above.

A typical biplane with monoplane body flattened to form a tail the tip of which is flexible enough steer aeroplane up and down. Note also the pointed flexible wing tips of the uppe

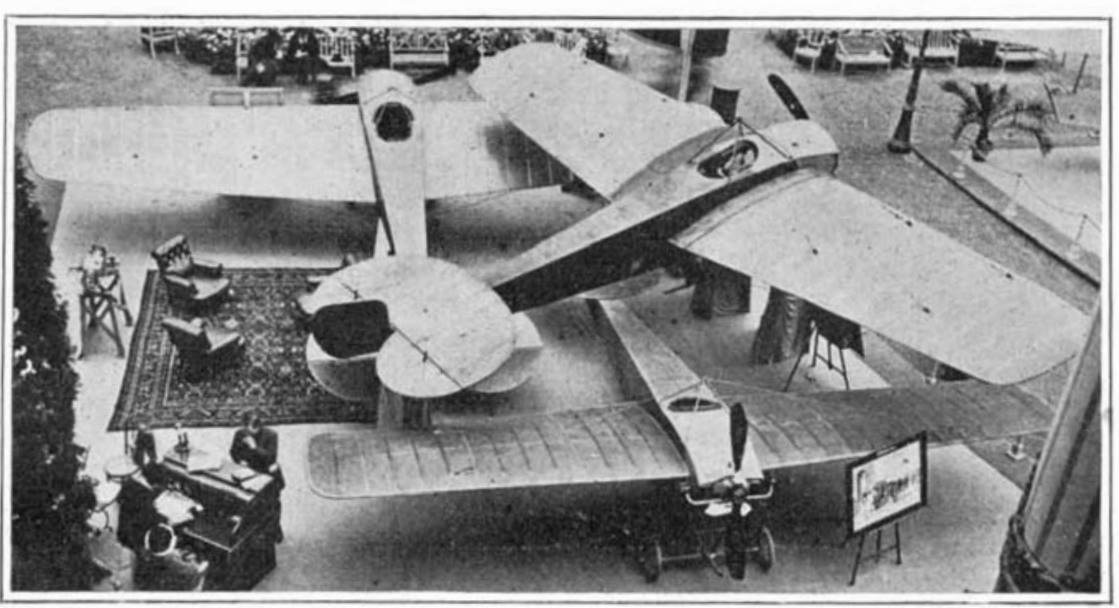

The Nieuport stand, showing three recent monoplanes.

The machine in the foreground is fitted with a 28 horse-power double-opposed-cylinder motor. It was with this motor that Nieuport had his first success and broke many speed records. NOVELTIES AT THE PARIS AERO SHOW teaux at the start of the Paris-Madrid race, is another builder employing allmetal construction, even of the wings. M. Train is a pioneer in this line, besides having the distinction of having flown an hour and twenty-five minutes at the Rheims meet, in August, 1910, with a motor of but 20 horse-power.

Although there was a distinct tendency toward the use of tor'pedo or fish-shaped bodies. Several monoplanes were shown without any body whatever except a short underslung car, with motor in front under a bonnet, the same as on an automobile. One such machine, the "Tubavion" of MM. Panché-Primard, is illustrated. A long tube forms the backbone and replaces the usual monoplane body. Converging, upwardlycurving skids attach to this tube at front and rear. The propeller is mounted on the tube behind the main plane, and is chain-driven from an extension of the engine shaft, which runs back beneath the pilot's seat. As no starting crank is provided, perhaps this machine is quite up-todate and is accordingly provided with a self-starter. The tubular backbone and underslung seat for the pilot remind one of the Grade monoplane, a leading German make that has found much favor.

England and Germany were represented at the Salon, which accordingly for the first time had somewhat of an international flavor. A Bristol monoplane, one of which, piloted by the Englishman, Valentine, made a sensational flight over Paris recently, was the chief representative of Great Britain, while an "Avi-
atic" monoplane and "Albatross" biplane gave an idea of German construction. This latter machine has flexible extensions of the main planes at the rear, as can be seen from the photograph, in place of ailerons. Suitable wires warp these extensions in much the same manner as on the Wright biplane. The Paulhan-Tatin torpedo monoplane, illustrated in our last issue, has upcurved wings which give sufficient automatic transverse stability so that, in the hands of an experienced pilot, no warping is needed. All the "Albatross" machines are fitted with double control. More than twenty have been sold to the German government, and six more have recently been ordered. IRussia is also a client of the Albatrosswerke. The "Albatross" biplane is typical of the latest biplanes in that it has a monoplane body which becomes flat at the rear and terminates in a horizontal rudder, while the vertical rudder, in the shape of a fin, is placed above the tail. Another point in which this machine is typical of the latest foreign biplanes is that the lower plane is very short. The struts connecting the two planes are, in this instance, arranged diagonally. This arrangement does away with the usual truss wires that were heretofore em. ployed.

The use of a flattened fuselage at the rear, with rudder above the tail, and elevator at its extremity, was inaugurated last summer by Blériot with his racer. IIe is now using it on his military-type machines, and its use has been adopted by most of the leading manufacturers.

There were many machines on exhibition having novel stabilizing devices, some of them for the maintenance of the equilibrium automatically. The Bronislawski stabilizer, słown in one of our photographs on a IIenry Farman biplane, consists of two small planes mounted on a vertical post. Normally these planes are in the position shown in the photograph, but when the machine tips, they are swung out until they are parallel with the main planes. These small planes at 
eacn end are worked in conjunction by the aviator. This device is said not to produce any turning of the aeroplane, and hence use of the vertical rudder to correct the same is not required. It consequently does not infringe the Wright patent.

A monoplane having a somewhat simi lar arrangement of the wings to that just described was one of the features of the show. This machine, known as the de Marcay and Mooney, had wings arranged so that they could be swung by the pilot from the regular position to a position parallel with and above the body. Upon alighting, the pilot can swing hi wings back and then run the machine along a road as an automobile.

There were a number of novelties and improved details about the various machines. Among those illustrated herewith is a small propeller which is revolved by the movement of the aeroplane through the air and is made to drive a pump for maintaining the air pressure in the fuel tank. There was also a biplane with electric headlights. This machine recalls the fact that aviator George M. Dyott made the first flight with an aeroplane fitted with electric headlights at Nassau Boulevard in America last October. Mr. Dyott used a dynamo for generating the electricity. Among the details to be noted are the hydroplane float of the Voisin "Canard" and the flat leaf springs used on the latest Blériot military monoplanes. The use of springs in con nection with skids is also coming into vogue and is shown on a number of machines, notably the "Albatross." The new Blériot fork makes it impossible for the wheels to give sideways if the machine does not land on both wheels at the same time. A skillful pilot is needed in orde to alight without breakage. In one $\mathrm{Mo}$ rane monoplane that was exhibited there were no shock absorbers of any kind, the under carriage resembling considerably that of Santos Dumont's "Demoiselle."

The exhibit of motors this year was very large. All told there were seventy motors on exhibition, varying in size from 25 to 200 horse-power. A number of these were of the rotary type, but the four-cylinder vertical water-cooled type was also in favor.

The Romance of Echoes $E_{\text {tic chapters in the book of Nature. }}^{\text {CHOES form one of the most roman }}$ Which are more severe tests of cre dulity - the echoes of fiction, or the echoes of fact? There is a tolerable repertory of the former, beginning with the antique fable of that lovely oread who pined away to "a voice and nothing more," and coming down to Paddy Blake, made famous by Samuel Lover:

"But civilly spake, 'How d'ye do, Paddy Blake?'

The echo politely says, 'Very well, thank you'."

However, these are but puerile attempts to vie with authentic marvels.

Some recent observations in Germany and Switzerland upon the reflection of sound from atmospheric strata miles above the earth's surface-which have opened up a new and, in the best sense romantic field of meteorological observa tion-make it timely to review the remarkable vagaries of echoes, as they have been recorded from time to time in all parts of the world.

Knowing that the sound-waves of the air are subject to reflections and other deviations analogous to those undergone by the light-waves of the ether, we might, on theoretical grounds alone, arrive at the conclusion that the echo is by no means a simple and uniform phenomenon. And so, in fact, we find that echoes are infinitely various.

Of the better-known remarkable echoes are two classes; (1) those which, owing to the great distance of the reflecting surface from the origin of the sound, send back the latter after a long interval, and are therefore able to repeat, for example. i large number of words or syllables after

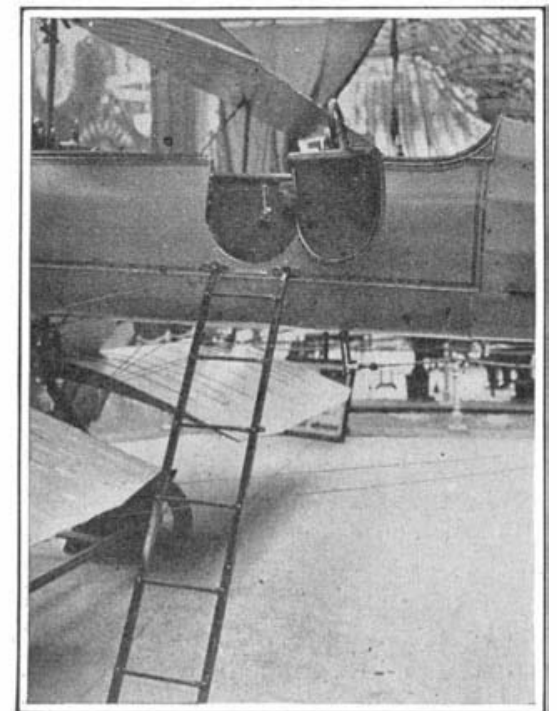

Breguet biplane body with side doo and ladder to mount.

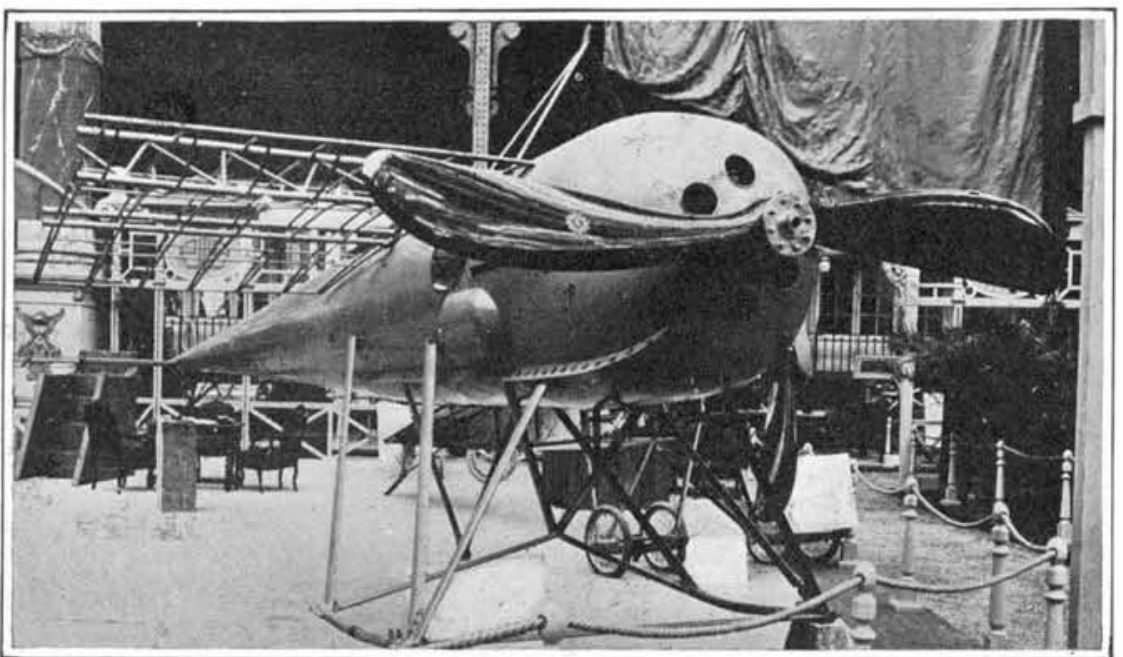

Torpedo shaped Morane monoplane body of pressed steel. The Gnome motor is completely inclosed. An uncovered section of one wing is seen out the left, in which the construction of steei tubing can be plainly seen.

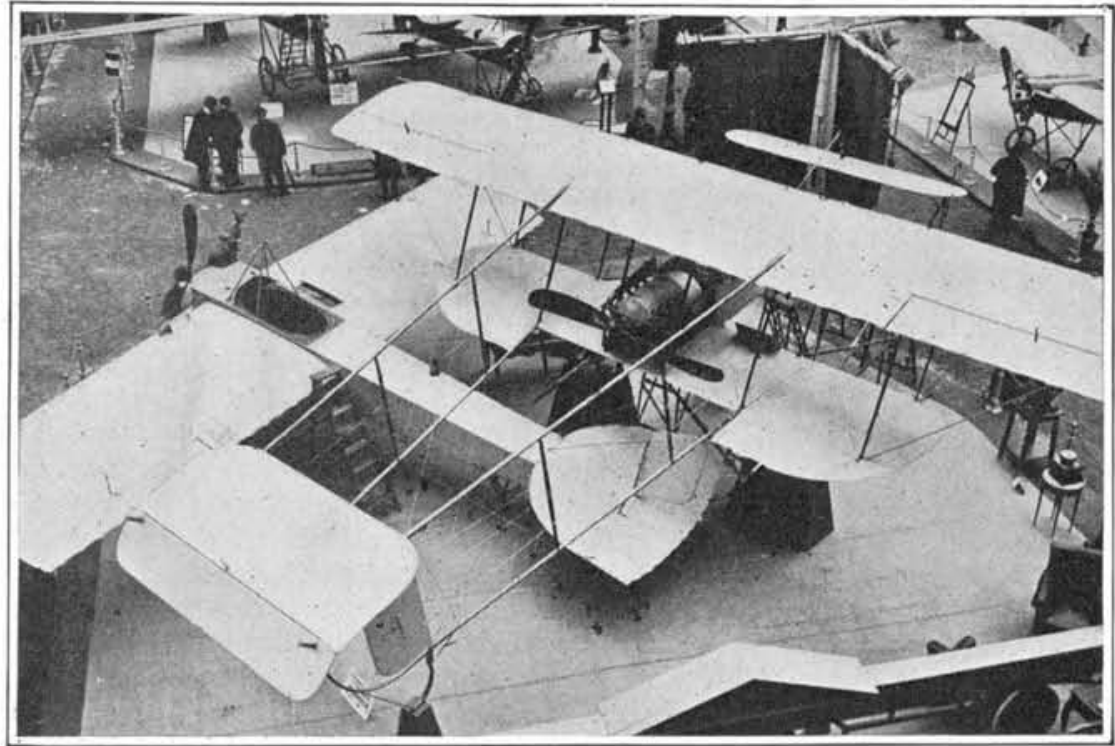

A Maurice Far'man biplane and a Henry Farman monoplane.

Both machines are of the latest type, having ailerons set into the wings. The biplane has stagfront and rear elevators are fitted; also twin vertical rudders.

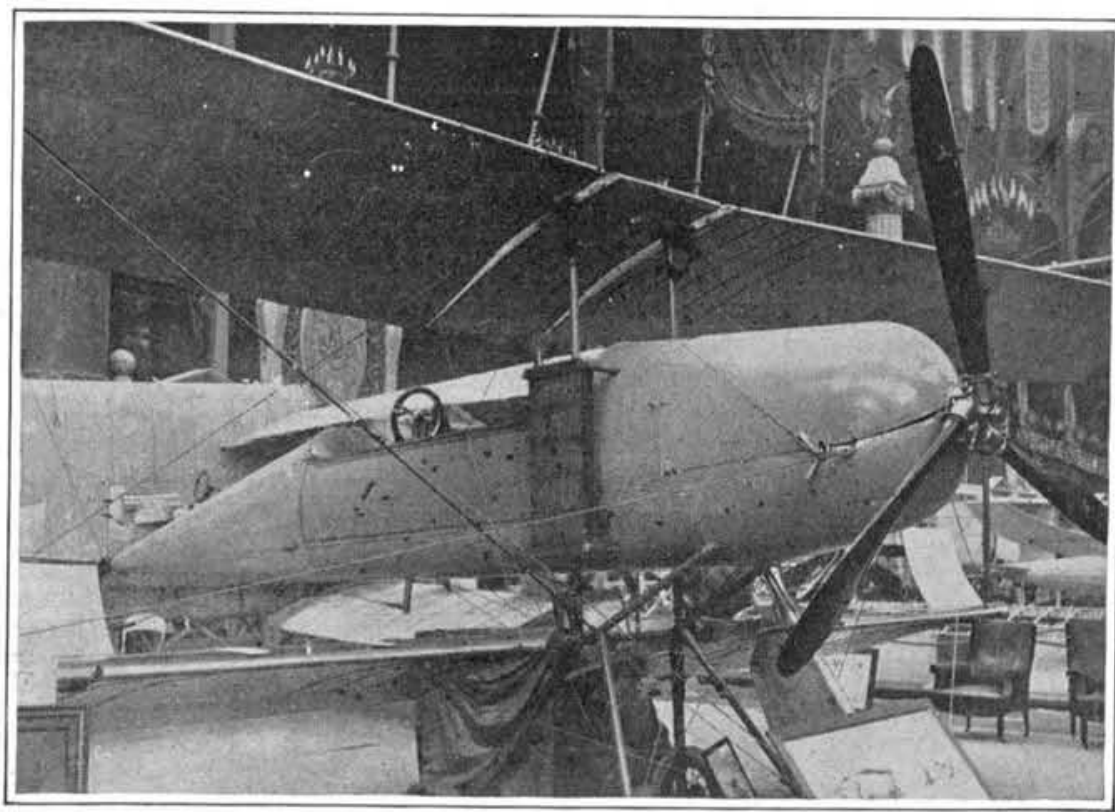

The latest Breguet biplane with inclosed motor and flexible 3-bladed propeller. The resemblance of the body of this machine to some of the recent automobile bodies produced abroad is striking.

NOVELTtes AT THE PARIS AERO SHOW the original sounds have ceased; and (2) those which, by successive reflections back and forth between two or more surfaces, repeat a single sound many times over. The most familiar instance of the first class is the echo in Woodstock Park, Oxfordshire, described by Sir John Herschel, which repeated seventeen syllables by day and twenty by night. Th's echo still holds its place in the school-books and guide-books, though it is, in fact, no longer heard, as some alterations in a bridge have completely silenced it The tomb of Cæcilia Metella, in the Roman campagna, has a famous echo that repeats a whole hexameter verse. In illustration of the second class Herschel cites the echo of Shipley Church, in Sussex, which repeated a syllable twenty-one times; but this echo, also, has vanished. Echoes are frail creatures; a slight change in the architecture of a building or the configuration of a landscape often suffices to extinguish them. All the old books on sound describe the echo of Simonetta Palace, near Milan, which according to the travelers of long ago ro peated a pistol-shot fifty or sixty times. Perhaps some of our Italian readers will tell us whether the story still holds good. These instances might be multiplied iudefinitely.

In many buildings may be observed the focussing of sound by vaulted ceilings and other curved surfaces; and whispering galleries are a part of th stock-in-trade of guides the world over. That of the Capitol, at Washington, is too well known to need description here. In the Hall of the Caryatides, in the Louvre, which has a cylindrically vaulted ceiling, there are two ancient basins of Sicilian alabaster, one at each end of the room. The slightest whisper uttered at the edge of one of these vases is distinctly heard by a person standing near the other, from which it appears to proceed. A similar acoustic effect is observed in the cathedral of Girgenti, Sicily. If you stand on the steps of the high altar you can distinctly hear anything that is said even in an undertone, at a spot near the threshold of the principal west entrance. 100 feet away. A story often told of this echo will bear repeating. It appears that one focus of the echo was unluckily chosen for the site of a confessional. The other focus was accidentally discovered by a gentleman, who for some time took great pleasure in overhearing the words intended solely for the confessor, and sometimes invited his friends to share in his amusement. One day, however, as the story runs, his own wife was in the confessional, and he and a friend thus became aware of secrets that were far from agreeable to the husband. Shortly afterward the confessional was moved. Whispering galleries are usually mere accidents of construction; but the famous "Ear of Dionysius," in the quarries of Syracuse, was said to have been designed for the purpose of enabling the tyrant to overhear the conversation of the prisoners in the dungeon adjoining his palace.

So far we have dealt only with echoes that slavishly imitate the sounds that come their way; but there are others possessing more originality. The proverbia! lrish echo, which we have mentioned among the echoes of fiction, is not so fictitious as might be supposed by any one unfamiliar with "harmonic echoes." The harmonic echo does not repeat the identical sound that it receives. Lord Rayleigh, who furnished an explanation of these echoes some years ago, quotes descriptions of several from Brewer. For example:

"On the river Nahe, near Bergen, and not far from Coblentz, is an echo thus described by Barthius: It makes seventeen repetitions at unequal intervals. Sometimes the echo seems to approach the listener, sometimes to be retreating from him; sometimes it is very distinct, at others extremely feeble; at one time it is heard at the right, and the next at (Concluded on page $\mathbf{z} 6$. ) 
The Comptometer appeals to the

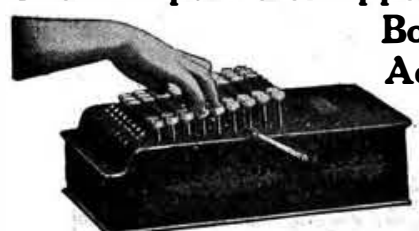

Bookkeeper, Accountant Bill - clerk the man who - because:

1. It does additions in half the time possible by any other means.

2. It is the only adding machine fast enough for practical figuring of chain disco'mts, extending and checking bills, payrolls, costs.
show you by practical demonstration.

3. It is easy to operate; even your typewriter, with a few weeks' practice, can figure faster and more accurately than a skilled accountant. Brain direction, machin

4. It saves time, money and worry by its rapid speed and sure accuracy. Used on all kinds of figuring by business houses all over the
world. - One business house alone has 181 Comptometers in daily use.

Let us send you a booklet about it; or machine on free trial, prepaid U. S. or Canada.

Felt \& Tarrant Mfg. Co.. 1708 N. Paulina St., Chicago, TYPEWRITERS ALLS, Visible Writers or otherwise
L.C.SMIrS. UNDERWODS.OLIVERS. Etc.
$1 / 4$ to $1 / 2$ MFRS. PRICES

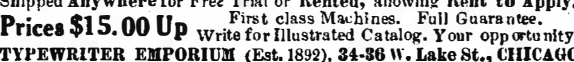

PENNSYLVANIA RAILROAD

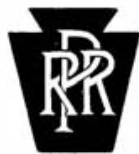

\section{Going to Chicago?}

One night to Chicago is what the Pennsylvania Special offers to the busy man. No time is lost from the business day. The banks and exchanges have been closed for an hour when the train leaves, and it reaches Chicago before they open the next morning.

An excellent dinner is served in a well appointed dining car.

The night may be passed according to the traveler's humor. He may work a while with a free stenographer at his elbow. He may read in the club or observation car or in his fitly lighted stateroom or berth. There is a club-like atmosphere in the smokeroom, where chat and smoke and refreshment combine to make the evening pass lightly.

In the berths and rooms there are clothes hangers, and the beds are comfortable in size and furnishing. The roadbed is solid, the cars steady, and the sleep is refreshing.

The morning bath and breakfast on the train fit a man for immediate work on rriva

This is travel with all drawbacks eliminated.

The Pennsylvania Special leaves New York, Pennsylvania Station, 4.00 P. M. Hudson Terminal 3.55 P. M. and arrives Chicago 8.55 A.M. bring many a nasty fall to the skater. with fog signals, in 1873. Tyndall found Ice is the solid form assumed by liquid on the other hand, that the sounds of
syrens and signal-guns were reflected by gelation or freezing. When what may the atmosphere even in the clearest for the moment be called liquid aerial
water-rain, freezes, we get hail-stones. He explained this effect as due
to a flocculent condition of the air arising water-rain, freezes, we get hail-stones. to a flocculent condition of the air arising But the water held in suspense by the atmosphere surrounding our earth is held
in the form of vapor. Saturation of the atmosphere with water-vapor is followe by condensation. This vapor in its consupported by the atmosphere which forth with lets it fall back to earth whence it was before, and will again be taken, up through the incessant evaporation. Deposits of condensed atmospheric vapor causes. When a warm vapor saturated area of our atmosphere is suddenly coole by contact with colder air-currents, or other causes, it undergoes condensation earth as rain, hail or snow. When saturated section of the lower atmosphere
comes in contact with a section of earth at a lower temperature, as during a summer night the surplus moisture in this
air falls as dew; in winter as hoar frost; air falls as dew; in winter as hoar frost; under conditions which are far rarer and seldom occur except locally, in high moun tain districts in early winter, the deposit takes the form of frost-flowers. These frost-flowers are identical in form with those other flowers, called snow flakes, Which are formed "in the clouds" or yet again the ice-flowers which, welded to-
gether by their natural expansion, cover pools of water with a sheet of ice in frosty weather-as already described. The white deposit of hoar-frost is also built of them. All invariably come into
existence as six-sided stars. There is no other type, but this type apart, the forms are of an infinite
been enumerated.

It is hardly possible to photograph those ice-stars, the birth of which pre cedes the change of liquid water into solid ice. To photograph snow-flakes is, again, not easy. The pictures accompanying this article are therefore all reproduced from jects coated with hoar-frost.

\section{The Romance of Echoes}

\section{(Concluded from page 69.)}

the left; now in unison with the direct tenth of the fundamental. Occasionally it seems to combine two or more voices in harmony, but more frequently it re Brewer also tells us that the celebrated echo of the Gap of Dunloe, in the lakes of Killarney, will render an ezcellent sec ond to a simple air played on a bugle This is merely an embroidered version of the true story, which is that if the
bugler chooses the right station and plays bugler chooses the right station and plays in the right tempo, the reflected notes will be heard at the same instant with different notes of the direct air, and may harmonize with them in many cases. This does not appear to be a true case of har monic echo. An unmistakable case was, viz., that of the echo at Bedgebury Park, the country residence of Mr. Beresford Hope. The sound of a woman's voice was returned from a plantation of firs,
situated across a valley, with the pitch raised an octave. The original sound and a man's voice would not produce the effect.

Rayleigh explained these echoes on the principle of selective refleetion. Just as small particles in the air will reflect light of short wave-lengths, but not that of
long wave-lengths-a fact that explains long wave-lengths - a fact that explains
the colors of the sky- so obstacles that are small in proportion to the length of the sound-waves will reflect only the smaller sound-waves; 1. e., those of high pitch. Thus, in the case of a composite note, such as that proceeding from the will return high-pitched overtones, or will return high-pitched overtones,
harmonics, but not the fundamental. Lastly, we come to aerial echoes; i. sounds reflected not by solid obstacle but by invisible acustic clouds in the atmosphere. Once upon a time it was believed that ordinary clouds, visible aggregations of water-drops, were potent reflectors of sound; and that, similarly, a These notions were effectually dispelled

by T'yndall as a result of his experiments rom unequal heating or moisture.

The latest episode in the romance of echoes-and one of the most romantichas to do with aerial reflections on a or the reason that it has suggested to meteorologists a novel method of inves. ar beyond the reach of kites and bal-

On November 15th, 1908, a magazine containing some 28 tons of dynamite exploded in a tunnel of the Jungfrau railway. The detonation was heard over a zone extending to the north and north (the configuration of the mountain pre-
(the for a distance of about 30 kilometers venting the propagation of the sound in other directions). Beyond this zone no sound whatever was heard over a region some 100 kilometers wide, embracing the strange to say, over a wide region begincountry and extending north into Germany the sound was heard. In other words, there was a zone of normal audibility, then a wide zone of silence, and then a zone of abnormal audibility, bepinning about 140 kilometers from the place of the explosion and ending about wilometers farther away. These facts teorologica established by the Swiss Meto collect reports from all parts of Switzerland and southern Germany, and published a map showing the places from which positive and negative information was received. Moreover, the same curious acoustic phenomenon had been obsions in Germany a few years before. How is this effect explained? Making due allowance for the acoustic shadows of sound due to vertical variations of wind and temperature, we must still seek an adequate explanation of the fact that the sound of the explosion jumped completely over a region 100 kilometers in
diameter, and, after pursuing a path diameter, and, after pursuing a path
through the air above the level of certain through the air above the level of certain
mountain observatories (from which mountain observatories (from which negative reports were received) returned of aerial reflection, and we must seek its In $h$ is recent studies on the stratification of the atmosphere ${ }^{1}$ Dr. Alfred Wesener offers the following explanation: The atmosphere is rather abruptly dimeters by the boundary plane between a stratum consisting chiefly of nitrogen
and one consisting chiefly of hydrogen The speed of sound is many times greater in the latter gas than in the former. Hence a sound-wave impinging on this boundary plane at a sufficiently great angle of inc:dence would undergo total reflection. If the plane of separation were sharply defined, and if no other causes conspired to deflect the path of he sound, it would, when propagated upward from the earth's surface, return to 40 kilometers from its place of origin. These conditions, however, are not fulThese conditions, however, are not ful-
filled, for the path is in the first place filled, for the path is in the first place
deflected by the ordinary causes of acous tic refraction, and in the second place it does not encounter a sharp plane of demarcation between the two gases. Taknds that the into account, Wegen radual curve the crest of which varies in altitude with the angle at which the sound leaves its origin. According to his the sound should return to the earth is 16 kilometers.

Why not, asks Wegener, reproduce the Jungfrau explosion experimentally? the alert to note results at a prearran on the alert to note results at a prearranged costly explosion would suffice to send message forty-odd miles above the earth and back again. The suggestion is for no means should be neglected that ing the, at present, decidedly problematial structure of the atmosphere above the level where it ceases to be air.-C. F. T. ' Physikalische Zeltachrift, March 1, 1911 ning near the northern border of the of the mountains, and for the refraction may lead to precise knowledge concern
One Dollar Puts the

RICHMOND:

Suction Cleaner

In Your Home

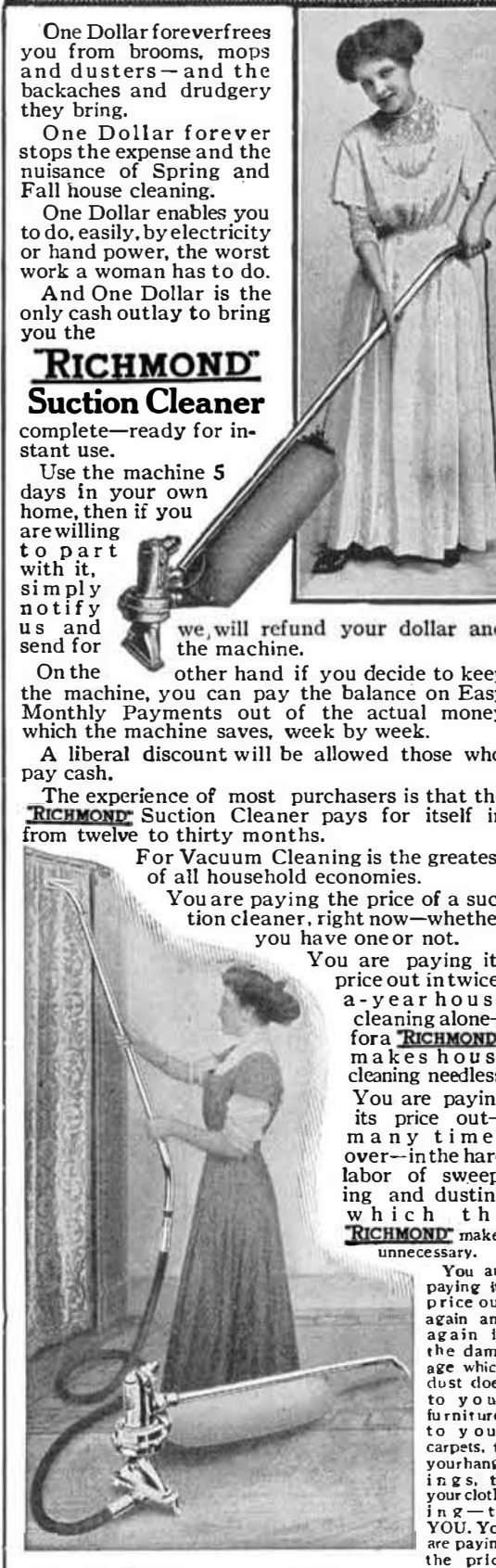

of a RTCHMOND when a single dollarwould save the waste.
:The RiCHMOND: Suction Cleaner weighs but ten pounds.

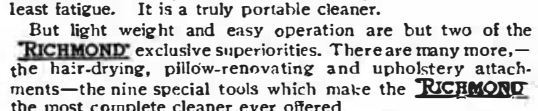

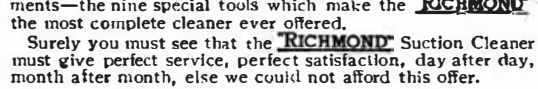

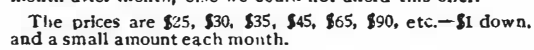

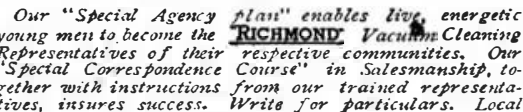

The MC Crum-Howerd Co.

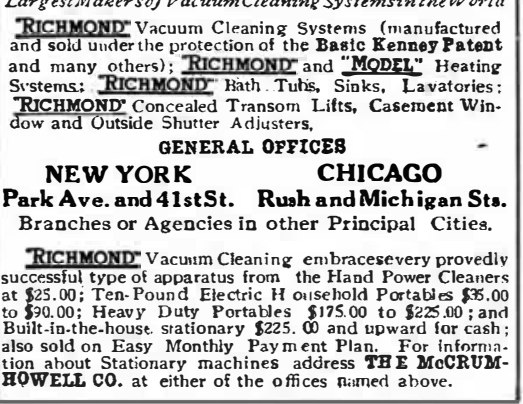

FreeTrial-No RedTape

The Richmond Sales Co.

103 R Park Ave., New York 